DOI: https://doi.org/10.33330/jurteksi.v6i2.437

Available online at http://jurnal.stmikroyal.ac.id/index.php/jurteksi

\title{
IMPLEMENTASI APLIKASI PENGELOLAAN SURAT MASUK DAN KELUAR BERBASIS WEB DI PRODI SISTEM INFORMASI
}

\author{
Dian Nurdiana \\ Sistem Informasi, Universitas Terbuka \\ email: dian.nurdiana@ecampus.ut.ac.id
}

\begin{abstract}
The Information Systems Study Program is one of the study programs at the Open University. The duties and responsibilities of the study program are managing academic and non-academic services. Management of incoming and outgoing mail is one of the tasks that must be carried out so that the service process is maximized. But the management is still manually so that problems occur such as difficulty in finding incoming or outgoing mail because it is still stored in folders, can only be accessed by one person because it is still stored on a computer and it is difficult to classify incoming mail. Therefore there must be a web-based incoming and outgoing mail management application. The purpose of this research is to implement a web-based incoming and outgoing mail application in the Information Systems Study Program. The model used for its development uses the waterfall model, while the testing model uses a black box. The results of this study are knowing the usability of implementing incoming and outgoing letters in the Information Systems Study Program.
\end{abstract}

Keywords: Black Boxes; Outgoing Letters; Incoming Letters; Waterfalls; Web Applications.

\begin{abstract}
Abstrak: Program Studi Sistem Informasi merupakan salah satu program studi yang ada di Universitas Terbuka. Tugas dan tanggung jawab program studi adalah mengelola layanan akademik maupun non akademik. Pengelolaan surat masuk dan surat keluar merupakan salah satu tugas yang harus dijalankan agar proses layanan menjadi maksimal. Namun pengelolaannya masih secara manual sehingga terjadi permasalahan seperti sulitnya mencari surat yang masuk atau surat yang keluar karena masih di simpan dalam folder-folder, hanya bisa di akses oleh satu orang karena masih disimpan dalam sebuah komputer dan sulit mengklasifikasikan surat yang masuk. Oleh sebab itu harus ada sebuah aplikasi pengelolaan surat masuk dan surat keluar berbasis web. Tujuan dari penelitian ini adalah mengimplementasikan aplikasi surat masuk dan surat keluar berbasis web di Program Studi Sistem Informasi. Model yang digunakan untuk pengembangannya menggunakan model watelfall, sedangkan model pengujiannya menggunakan black box. Hasil dari penelitian ini adalah mengetahui usability dari implementasi surat masuk dan surat keluar di Program Studi Sistem Informasi
\end{abstract}

Kata kunci: Aplikasi Web; Black Box; Surat Keluar; Surat Masuk; Waterfall. 
JURTEKSI (Jurnal Teknologi dan Sistem Informasi)

Vol. 6 No. 2, April 2020, hlm. 135 - 144

DOI: https://doi.org/10.33330/jurteksi.v6i2.437

Available online at http://jurnal.stmikroyal.ac.id/index.php/jurteksi

\section{PENDAHULUAN}

Manfaat IT dalam perkembangan kehidupan sehari-hari memang sangat banyak, terutama untuk pendidikan, industri, internet, dan berbagai bisnis dan dunia lainnya. Teknologi informasi memiliki peran yang sangat vital terutama untuk dunia bisnis dan pendidikan[1]-[4]. Organiasi maupun bisnis tanpa memanfaatkan organisasi dalam proses operasi-onalnya cendrung kendur. Sehingga banyak organisasi maupun bisnis memanfaatkan teknologi informasi untuk membantu proses pengelolaan operasional meraka. Selain digunakan untuk membantu dalam dunia bisnis, pemanfaatan IT saat ini sudah merambah di segala bidang termasuk dalam pengelolaan administrasi surat menyurat.

Menurut Lawrence Setiap organisasi baik pemerintahan maupun swasta harus dapat mengelola informasi secara cepat dan tepat dengan menggunakan sebuah aplikasi untuk mencari, mengatur dan menyimpan agar informasi tersedia saat dibutuhkan juga berkaitan dengan kepentingan banyak pihak di dalam organisasi tersebut [5], [6]. Surat merupakan media komunikasi yang digunakan untuk berkomunikasi antara dua belah pihak. Informasi yang ada dalam surat bisa mengandung informasi, pernyataan, kritikan pemberitahuan, pernyataan, permintaan ataupun laporan [7]. Korespondensi merupakan hubungan surat menyurat saling berbalasan. Setiap organisasi baik yang skalanya kecil maupun besar melakukan proses surat dimana sipengirim dan penerima
ISSN 2407-1811 (Print)

ISSN 2550-0201 (Online) menyurat. Agar informasinya sampai dengan benar maka surat harus ditulis dengan bahasa dan tulisan yang jelas serta maksud yang disampaikanya jelas.

Surat digunakan sebagai bukti autentik sehingga mempunyai nilai yang sangat penting bagi organisasi pemerintahan maupun swasta. Surat menunjukkan dinamika kehidupan suatu kantor maupun organiasasi sebagai alat komunikasi, sebagai pusat ingatan, dan sebagai dokumentasi. Sehingga dalam pengelolaanya harus dilakukan sebaik mungkin dan bisa mengikuti proses perkembangannya.

Dalam pelaksanaannya saat ini pengelolaan surat menyurat masih menggunakan sistem yang manual di mana terdapat beberapa masalah yang menghambat proses pengaksesan data surat [8]-[10], misalnya sulitnya mencari data surat masuk, surat keluar maupun surat disposisi, sulitnya menampilkan data surat mana saja yang masih diperlukan ataupun sudah harus dibuang (dihapus). Semua itu dikarenakan pengolahan data-datanya masih secara manual dan belum terkomputerisasi.

Tujuan dari penelitian ini adalah mengimplementasikan aplikasi surat masuk dan surat keluar di Program Studi Sistem Informasi Universitas Terbuka yang bertujuan untuk membantu dalam pengelolan surat masuk dan surat keluar di Program Studi. Aplikasi yang digunakan merupakan aplikasi bersifat open source yang diambil dari https://members.phpmu.com/kontribus i/detail/aplikasi-sederhanamanajemen-surat-dengan-php-mysqli dengan nama Aplikasi Surat Masuk dan Surat Keluar dengan PHP MySql 
JURTEKSI (Jurnal Teknologi dan Sistem Informasi)

Vol. 6 No. 2, April 2020, hlm. 135 - 144

DOI: https://doi.org/10.33330/jurteksi.v6i2.437

Available online at http://jurnal.stmikroyal.ac.id/index.php/jurteksi

namun dengan beberapa penyesuaian yang dibutuhkan oleh Program Studi Sistem Informasi Universitas Terbuka. Aplikasi berbasis web menjelaskan bahwa munculnya Web 3.0 merupakan integrasi dari Web 1.0 dan Web 2.0 adalah aplikasi berskala besar yang mengembangkan teknologi jaringan digital dan dapat mendukung kerja sama manusia dalam hal ini suatu organisasi [11].

\section{METODE}

Tahapan penelitian dalam Aplikasi surat masuk dan keluar ini dapat dilihat pada gambar 2 sebagai berikut:

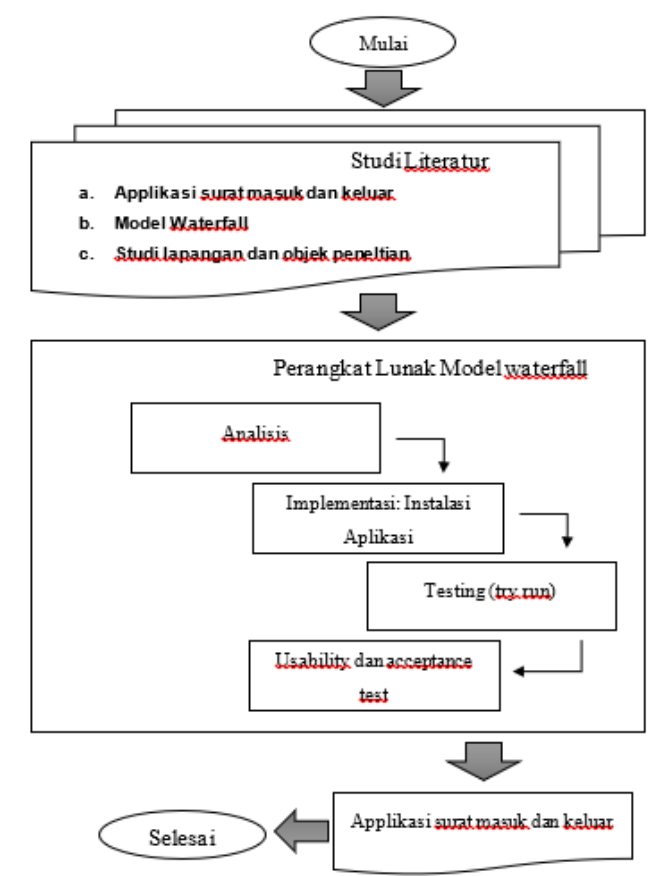

Gambar 1. Tahapan Penelitian

Tahapan penelitian yang telah digambarkan pada gambar 2 dapat jelaskan sebagai berikut:

1. Studi Literatur

Tahap pertama dalam pene-litian ini adalah studi literatur. Dalam studi literatur ini terdapat tiga tahapan yaitu tentang Aplikasi surat masuk dan keluar dan model waterfall sebagai perangkat lunak kemudian penggunaan model waterfall yang akan digunakan dan studi lapangan berserta objek penelitiannya.

2. Perangkat Lunak Model Waterfall Pembangunan Aplikasi surat masuk dan keluar ini menggunakan model waterfall. Model ini memiliki tahapannya diantaranya tahap analisis, tahap implementasi berupa proses install aplikasi, kemudian tahap testing dan tahap Usability dan acceptance test

Teknik yang digunakan dalam penelitian ini adalah teknik wawancara dan observasi. Teknik wawancara dilakukan terhadap ketua program Studi Sistem Informasi Universitas Terbuka. Teknik wawancara ini akan menghasilkan requirement yang diinginkan untuk mengimplementasikan sebuah Aplikasi surat masuk dan keluar.

Penelitian ini akan dilaksanakan di Program Studi Sistem Informasi Fakultas Sains dan Teknologi Universitas Terbuka. Metode yang telah dipublikasikan harus ditunjukkan dengan referensi yang sesuai pada bagian daftar pustaka. Apabila terdapat modifikasi yang relevan, maka hal tersebut juga harus dijelaskan.

\section{HASIL DAN PEMBAHASAN}

\section{Analisis}

Pada tahap analisis ini dibagi menjadi dua tahap, yaitu analisis 
JURTEKSI (Jurnal Teknologi dan Sistem Informasi)

Vol. 6 No. 2, April 2020, hlm. 135 - 144

DOI: https://doi.org/10.33330/jurteksi.v6i2.437

Available online at http://jurnal.stmikroyal.ac.id/index.php/jurteksi

kebutuhan dan analisis pemilihan aplikasi

\section{Analisis Kebutuhan}

Setiap instansi tidak lepas dari kegiatan operasional yang berhubungan dengan pelayanan atau pendokumentasian arsip, salah satunya adalah pengelolaan surat masuk dan surat keluar. Hal ini penting karena surat masuk dan surat keluar merupakan arsip yang harus didokumentasikan dan disimpan sebaik mungkin karena bisa dibutuhkan pada waktu tertentu. Oleh sebab itu Program Studi Sistem Informasi merupakan salah satu bagian dari instansi yang harus menjaga pengelolaan surat masuk dan surat keluar agar pengelolaannya baik.

Dari hasil wawancara dengan ketua program studi sistem informasi menyampaikan bahwa penggunaan aplikasi surat masuk dan keluar dirasa sangat dibutuhkan untuk pengarsipan surat yang ada di lingkungan program studi sistem informasi. Aplikasi yang digunakan nantinya diharapkan berbasis website sehingga dapat diakses dimana saja dan oleh siapa saja. Untuk bisa mengoptimalkan kinerja ke depannya aplikasi diharapkan bisa di modifikasi dan dikembangkan sesuai dengan kebutuhan program studi.

\section{Analisis Aplikasi}

Dalam penelitian ini aplikasi yang digunakan adalah aplikasi yang bersifat open source dan mudah dikembangkan. Pemilihan aplikasi yang akan digunakan dalam penelitian surat masuk dan surat keluar yang akan diimplementasi di program studi Sistem Informasi ini perlu dilakukan menjadi sangat penting sehingga

\begin{abstract}
nantinya ketika diimplementasikan diharapkan dapat digunakan dan sesuai dengan kebutuhan yang ada
\end{abstract}

\section{Analisis Desain aplikasi}

Setelah melakukan analisis pemilihan aplikasi yang akan digunakan maka tahap selanjutnya adalah menganalisis desain aplikasi yang akan digunakan. Fungsi dari analisis ini bertujuan untuk lebih mengetahui desain dan rancangan aplikasi sehingga bisa digunakan sebagai acuan dalam penggunaan maupun dalam pengembangan aplikasi selanjutnya. Analisis desain aplikasi ini meliputi beberapa desain antara lain:

1. Data Flow Diagram (DFD)

Data Flow Diagram (DFD) adalah representasi grafik yang menggambarkan aliran informasi dan transformasi informasi yang diaplikasikan sebagai data yang mengalir dari masukan (input) dan keluaran (output) [12].

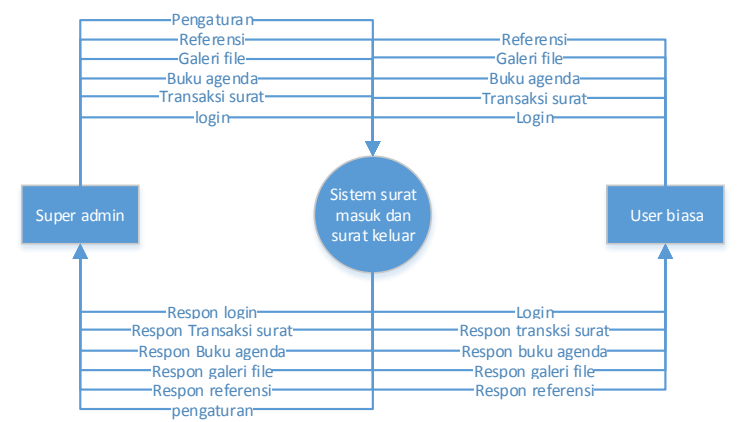

Gambar 2. DFD level 0

Dalam DFD level 0 pada sistem surat masuk dan surat keluar menjelaskan ada 2 buah pengguna yang berkaitan dengan sistem yaitu super admin dan user biasa. Perbedaan dengan super admin yaitu user biasa tidak bisa 
DOI: https://doi.org/10.33330/jurteksi.v6i2.437

Available online at http://jurnal.stmikroyal.ac.id/index.php/jurteksi

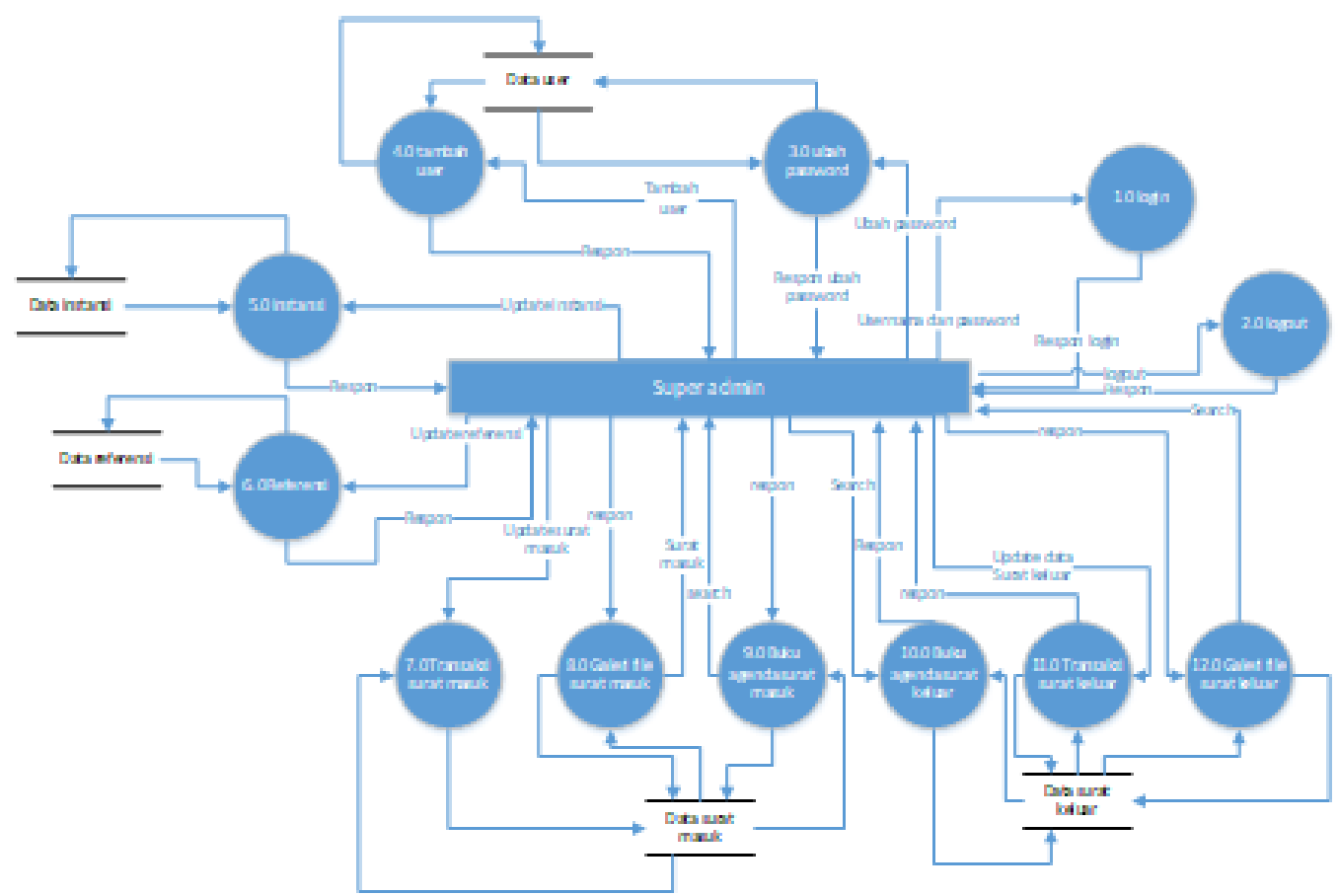

Gambar 3. DFD Level 1

mengakses halaman pengaturan.

\section{Database}

Database adalah basis data adalah kumpulan data yang terbagi dan terhubung secara logikal dan deskripsi dari data yang dirancang untuk memenuhi kebutuhan informasi suatu organisasi [13]. Sedangkan menurut Hoffer database adalah sekumpulan organisasi data yang berelasi secara logika [14]. Pada aplikasi surat masuk dan keluar ini setelah dianalisis dapat digambarkan mempunyai struktur database gambar 5 .

3. Struktur menu

Perancangan struktur menu bertujuan untuk memudahkan dalam penggunaan fungsi-fungsi program yang ada pada Sistem
Informasi Pengarsipan Surat Masuk dan Surat Keluar. Dari hasil analisa yang telah dilakukan, aplikasi surat masuk dan keluar memiliki struktur menu seperti pada gambar 4 .

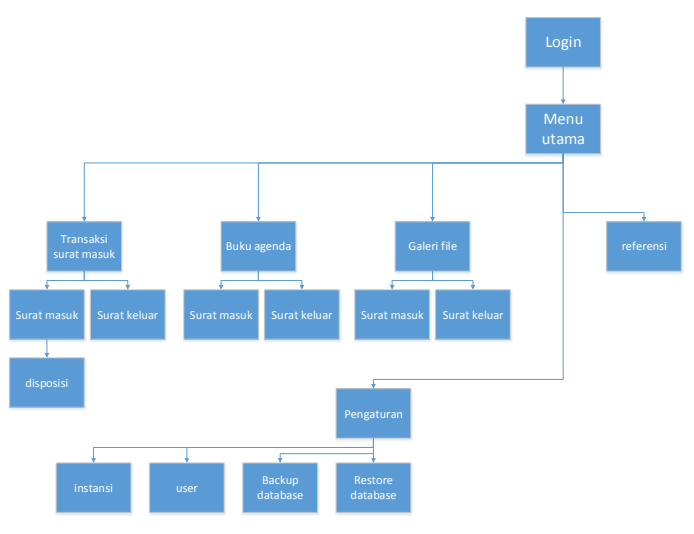

Gambar 5. struktur menu 
DOI: https://doi.org/10.33330/jurteksi.v6i2.437

Available online at http://jurnal.stmikroyal.ac.id/index.php/jurteksi

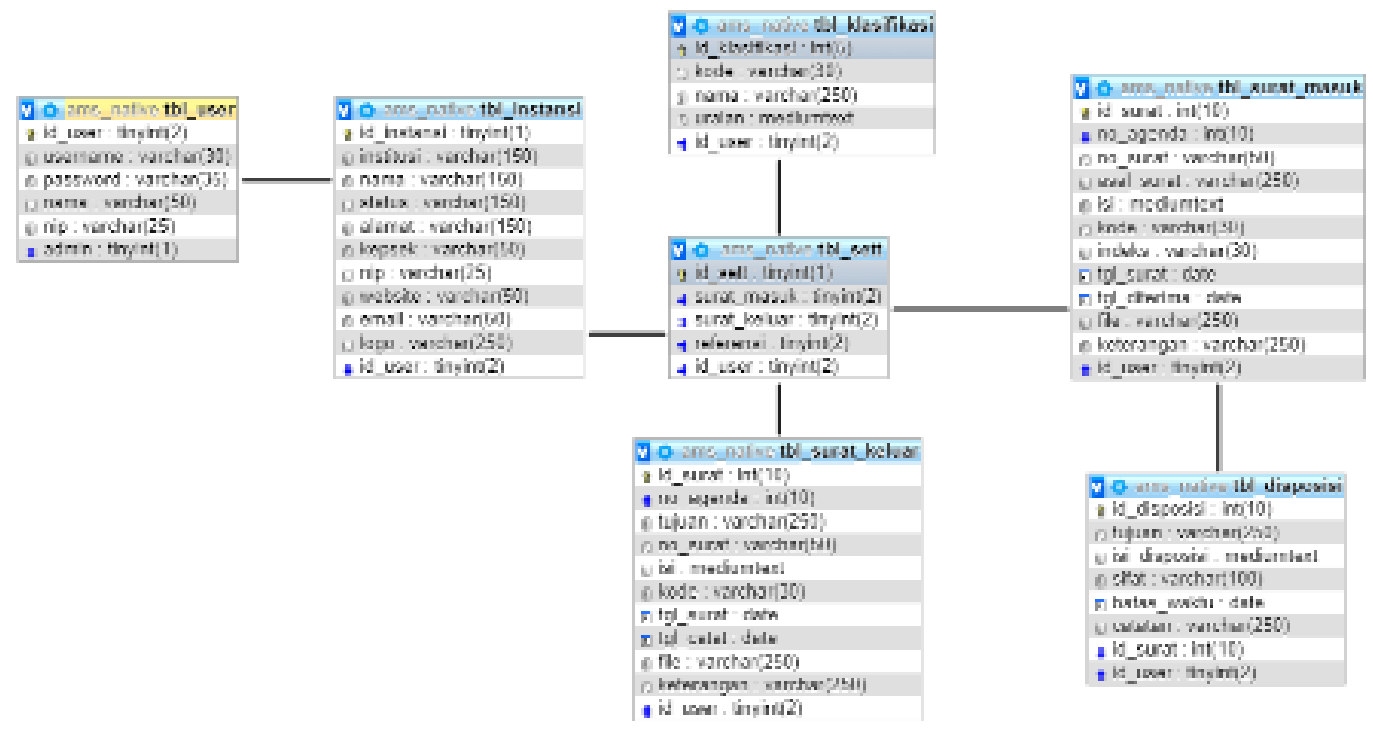

\section{Gambar 5. DFD Level 1}

Dari struktur menu diatas dapat dilihat menu yang paling atas adalah tampilan login kemudian setelah login akan masuk ke menu utama. Didalam menu utama ada beberapa menu antara lain:

1. Transaksi surat masuk yang terdiri dari surat masuk dan surat keluar.

2. Disposisi dilakukan pada menu surat masuk

3. Buku agenda yang terdiri dari surat masuk dan surat keluar.

4. Galeri file yang terdiri dari surat masuk dan surat keluar

5. Referensi.

6. Pengaturan yang terdiri dari instansi, user, backup database dan restore database

\section{Implementasi}

Setelah tahap analisis dilalui secara komprehensif, selanjutnya masuk kepada tahap implementasi yang bertujuan untuk mengistal aplikasi yang akan digunakan. Pada tahap ini dipastikan apakah semua infrastruktur yang dibutuhkan baik berupa perangkat keras, periferal dan lainnya sudah siap digunakan. Selain infrastruktur yang dibutuhkan pada tahap ini juga harus memastikan servis pendukung untuk jalannya aplikasi sudah terinstal dengan baik dan mem-

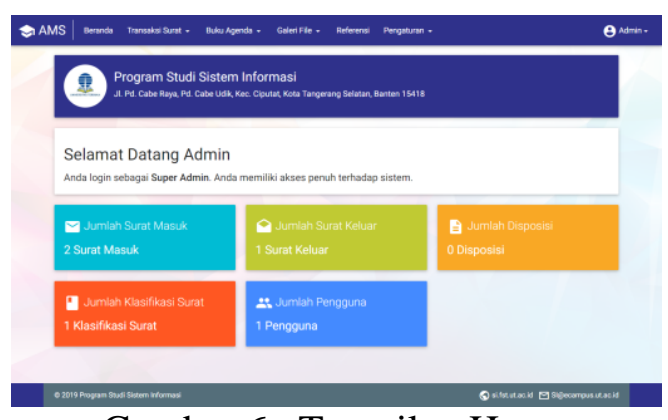

Gambar 6. Tampilan Home

punyai kompabilitas yang sama dengan kebutuhan aplikasi yang akan digunakan. Pada tahap implementasi harus melibatkan tim ahli yang memahami proses instalasi aplikasi yang akan digunakan.

\section{Testing}

Black box testing adalah 
JURTEKSI (Jurnal Teknologi dan Sistem Informasi)

Vol. 6 No. 2, April 2020, hlm. 135 - 144

DOI: https://doi.org/10.33330/jurteksi.v6i2.437

Available online at http://jurnal.stmikroyal.ac.id/index.php/jurteksi

menguji perangkat lunak dari segi spesifikasi fungsional tanpa menguji desain dan kode program [15]. Pengujian dimaksudkan untuk mengetahui apakah fungsi-fungsi, masukan, dan keluaran dari perangkat lunak sesuai dengan spesifikasi yang dibutuhkan. Pengujian kotak hitam dilakukan dengan membuat kasus uji yang bersifat mencoba semua fungsi dengan memakai perangkat lunak apakah sesuai dengan spesifikasi yang dibutuhkan (tabel 1).
ISSN 2407-1811 (Print)

ISSN 2550-0201 (Online)

\section{Usability dan acceptance test}

Tahap ini merupakan kegiatan yang bertujuan melakukan validasi fungsional dan penerimaan aplikasi kepada pengguna [16]. Pengujian difokuskan pada tipe validasi dan pengujian terhadap fungsi-fungsi yang dibutuhkan sudah tercukupi. Melihat fungsi yang telah ada apakah berjalan dengan yang diharapkan. Dilakukan pengujian dengan data yang benar dan salah. Selanjutnya menyimpulkan hasil pengujian ini apakah sudah layak atau belum (tabel 2).

Tabel 1. Pengujian Black Box

\begin{tabular}{|l|c|}
\hline \multicolumn{1}{|c|}{ Skenario Pengujian } & Keterangan \\
\hline Pengujian halaman login & Diterima \\
\hline Pengujian halaman utama & Berhasil \\
\hline Pengujian pengaturan instansi & Berhasil \\
\hline Pengujian menu penambahan user & Berhasil \\
\hline Pengujian tambah user & Berhasil \\
\hline Pengujian edit profile & Berhasil \\
\hline Pengujian halaman ubah password & Berhasil \\
\hline Pengujian halaman backup database & Berhasil \\
\hline Pengujian halaman restore database & Berhasil \\
\hline Pengujian referensi surat & Berhasil \\
\hline Pengujian halaman tambah klasifikasi surat & Berhasil \\
\hline Pengujian halaman daftar surat masuk & Berhasil \\
\hline Pengujian halaman menambah data surat masuk & Berhasil \\
\hline Pengujian halaman daftar surat keluar & Berhasil \\
\hline Pengujian halaman tambah data surat keluar & Berhasil \\
\hline Pengujian halaman cetak agenda surat masuk & Berhasil \\
\hline Pengujian halaman cetak agenda surat keluar & Berhasil \\
\hline Pengujian halaman galeri surat masuk & Berhasil \\
\hline Pengujian halaman galeri surat keluar & Berhasil \\
\hline Pengujian halaman edit surat masuk & Berhasil \\
\hline Pengujian halaman print surat masuk & Berhasil \\
\hline Pengujian halaman disposisi surat masuk & Berhasil \\
\hline Pengujian halaman edit surat keluar & Berhasil \\
\hline Pengujian halaman detail surat masuk & Berhasil \\
\hline Pengujian halaman detail surat keluar & Berhasil \\
\hline
\end{tabular}


JURTEKSI (Jurnal Teknologi dan Sistem Informasi)

Vol. 6 No. 2, April 2020, hlm. 135 - 144

DOI: https://doi.org/10.33330/jurteksi.v6i2.437

Available online at http://jurnal.stmikroyal.ac.id/index.php/jurteksi

Tabel 2. Angket Hasil Pengujian

\begin{tabular}{|l|l|l|l|l|l|}
\hline \multirow{2}{*}{ No. } & \multicolumn{3}{|c|}{ Pertanyaan } & \multicolumn{3}{c|}{ Jawaban } \\
\cline { 3 - 6 } & & SS & S & TS & STS \\
\hline 1 & Saya berpikir akan menggunakan aplikasi ini & & $\sqrt{ }$ & & \\
\hline 2 & Saya merasa aplikasi ini mudah digunakan & $\sqrt{ }$ & & & \\
\hline 3 & $\begin{array}{l}\text { Saya membutuhkan bantuan dari orang lain atau } \\
\text { teknisi dalam menggunakan aplikasi ini }\end{array}$ & & $\sqrt{ }$ & & \\
\hline 4 & $\begin{array}{l}\text { Aplikasi mudah dipelajari oleh orang yang pertama } \\
\text { kali menggunakannya }\end{array}$ & $\sqrt{ }$ & & & \\
\hline 5 & $\begin{array}{l}\text { Meskipun pemakai telah lama tidak menggunakan } \\
\text { aplikasi tersebut, akan mudah menggunakannya } \\
\text { lagi }\end{array}$ & & $\sqrt{ }$ & & \\
\hline 6 & $\begin{array}{l}\text { Saya merasa fitur-fitur aplikasi ini berjalan dengan } \\
\text { baik }\end{array}$ & & & $\sqrt{ }$ & \\
\hline 7 & $\begin{array}{l}\text { Informasi yang dihasilkan oleh aplikasi yang } \\
\text { digunakan sesuai dengan yang saya butuhkan }\end{array}$ & & $\sqrt{ }$ & & \\
\hline 8 & $\begin{array}{l}\text { Aplikasi yang digunakan manghasilkan laporan } \\
\text { yang saya butuhkan }\end{array}$ & & & $\sqrt{ }$ & \\
\hline 9 & $\begin{array}{l}\text { Aplikasi yang digunakan mampu memberikan } \\
\text { informasi sesuai dengan format yang dibutuhkan }\end{array}$ & & & $\sqrt{ }$ & \\
\hline 10 & $\begin{array}{l}\text { Saya dapat memperoleh informasi yang saya } \\
\text { butuhkan tepat waktu dan dimana saja }\end{array}$ & & $\sqrt{ }$ & & \\
\hline
\end{tabular}

\section{SIMPULAN}

Berdasarkan hasil wawancara terkait dengan permasalahan yang dihadapi oleh Program Studi Sistem Informasi Universitas Terbuka dihasilkan solusi dengan mengimplementasikan sebuah aplikasi surat masuk dan surat keluar berbasis web.

Aplikasi yang digunakan merupakan aplikasi yang bersifat open source dan di modifikasi sesuai dengan kebutuhan pada Program Studi Sistem Informasi. Pemilihan aplikasi dilakukan dengan membandingkan dengan aplikasi yang sejenis.

Usability aplikasi dilakukan dengan cara pengujian terhadap aplikasi. Pengujian dilakukan dengan 2 tahapan. Tahap pertama menggunakan pengujian black box dengan hasil $100 \%$ berhasil. 
DOI: https://doi.org/10.33330/jurteksi.v6i2.437

Available online at http://jurnal.stmikroyal.ac.id/index.php/jurteksi

BERBASIS WEB PADA SD ISLAM LUQMANUL HAKIM BEKASI," Jurteksi, vol. 6, no. 1, pp. 71-78, 2019.

[3] M. L. Sibuea and A. Safta, "Pemetaan Siswa Berprestasi Menggunakan Metode KMeans Clustring," Jurteksi, vol. 4, no. 1, pp. 85-92, 2017.

[4] E. L. Febrianti and T. Christi, "Peneraan Forward Chaining Untuk Mendianogsa Penyakit Malaria Dan Pencegahanya Berbasis Web," Jurteksi, vol. 4, no. 1, pp. 93-100, 2017.

[5] L. W. Serewicz, "Do we need bigger buckets or better search engines?," Rec. Manag. J., 2010.

[6] A. D. L. Tarigan and J. Jumino, "PEMANFAATAN APLIKASI E-SURAT DALAM MENDUKUNG

PENGELOLAAN ARSIP DINAMIS AKTIF DI DINAS KEARSIPAN DAN PERPUSTAKAAN PROVINSI JAWA TENGAH,” $J . \quad$ Ilmu Perpust., vol. 7, no. 3, pp. 7180, 2018.

[7] H. T. Sihotang, "Sistem Informasi Pengagendaan Surat Berbasis Web Pada Pengadilan Tinggi Medan," J. Inform. Pelita Nusant., vol. 3, no. 1, 2018.

[8] B. Rahman, B. Susetyo, B. J. K. S. I. Primasari, D., KM, and K. Badak, "Analisis kinerja pelayanan surat-menyurat berbasis web di pgri kabupaten bogor," Inform. J. Komput. Dan Inform., vol. 3, no. 1, pp. 1-12, 2019.

[9] A. N. Garnasih, T. Hartati, and
M. Wijiyanti, "ANALISIS PENGELOLAAN SISTEM SURAT MENYURAT DENGAN SISTEM MANUAL DAN SISTEM NOTA DINAS ONLINE DALAM UPAYA MENINGKATKAN PENGENDALIAN SURAT PADA PT ANEKA TAMBANG (PERSERO) TBK.-UNIT GEOMIN," Epigram, vol. 15, no. 1, 2018.

[10] S. Mahmudah, L. Widiastuti, and S. Ernawati, "Sistem Informasi Manajemen Pengarsipan Surat Masuk Dan Surat Keluar (Studi Kasus: Ma Darul Ihya Bogor)," J. MEDIA Inform. BUDIDARMA, vol. 3, no. 3, pp. 225-231, 2019.

[11] D. R. Soriano, F. J. GarrigosSimon, R. L. Alcamí, and T. B. Ribera, "Social networks and Web 3.0: their impact on the management and marketing of organizations," Manag. Decis., 2012.

[12] R. A. Sukamto and M. Shalahuddin, "Rekayasa perangkat lunak terstruktur dan berorientasi objek," Bandung Inform., vol. 3, 2013.

[13] T. M. Connolly and C. E. Begg, Database systems: a practical approach to design, implementation, and management. Pearson Education, 2005.

[14] J. A. Hoffer, V. Ramesh, and H. Topi, Modern database management. Upper Saddle River, NJ: Prentice Hall, 2011.

[15] A. S. Rosa and M. Salahuddin, "Modul Pembelajaran Rekayasa Perangkat," Lunak (Terstruktur 
DOI: https://doi.org/10.33330/jurteksi.v6i2.437

Available online at http://jurnal.stmikroyal.ac.id/index.php/jurteksi

dan Berorientasi Objek), 2011.

[16] Y. Nurhadryani, S. K. Sianturi, I. Hermadi, and H. Khotimah, "Pengujian usability untuk meningkatkan antarmuka aplikasi mobile," J. Ilmu Komput. dan Agri-Informatika, vol. 2, no. 2, pp. 83-93, 2013. 